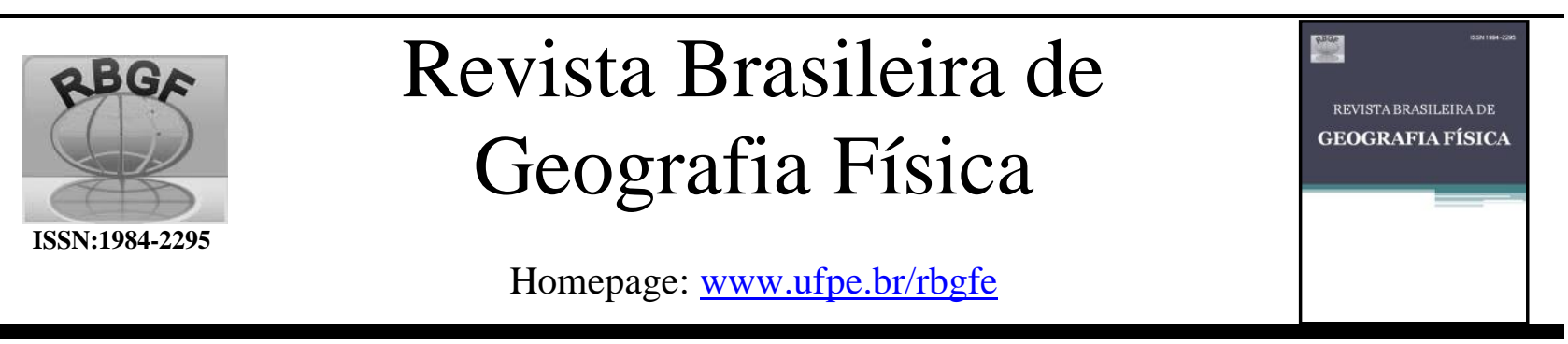

\title{
Fenologia de samambaias e licófitas no Brasil: uma abordagem metodológica e ecológica
}

\author{
Andressa Müller ${ }^{1,3}$; Jairo Lizandro Schmitt ${ }^{2,3}$ \\ ${ }^{1}$ Doutora em Qualidade Ambiental, Autor Correspondente: e-mail: biol.andressa@gmail.com ${ }^{2}$ Doutor em \\ Botânica, Professor Titular do Programa de Pós-Graduação em Qualidade Ambiental, e-mail: \\ jairols@ feevale.br ${ }^{3}$ Laboratório de Botânica, Universidade Feevale, ERS-239, 2755, CEP 93525-075, Novo \\ Hamburgo, RS, Telefone: (51) 3586-8800, Ramal 9003.
}

Artigo recebido em 30/05/2019 e aceito em 02/09/2019

R E S U M O

Samambaias são plantas vasculares sem sementes que se distribuem em uma variedade de ecossistemas, dos trópicos à região boreal e ocupam desde o estrato herbáceo até o arborescente. Fenologia é uma ciência ambiental integrativa que estuda os eventos vegetativos e reprodutivos das plantas e a sua relação com o clima. Estudos fenológicos com samambaias têm sido realizados ao longo do território brasileiro há cerca de 36 anos, com plantas monitoradas principalmente nas regiões sul e nordeste do país. Diversos enfoques podem ser dados ao monitoramento fenológico, visando entender a influência do clima no desencadeamento das fenofases, o crescimento e o desenvolvimento das plantas. Desta forma, por meio de extensa revisão na literatura científica, este artigo objetiva abordar e construir um cenário fenológico brasileiro para as espécies de samambaias e licófitas monitoradas no país, além de compilar as abordagens metodológicas necessárias para alcançar as respostas fenológicas dessas plantas, assim como novas perspectivas de pesquisa e lacunas no campo do conhecimento a serem preenchidas.

Palavras-chave: Clima, Fenofase, Monitoramento.

\section{Phenology of fern and lycophyte in Brazil: a methodological and ecological approach}

\begin{abstract}
A B S T R A C T
Ferns are seedless vascular plants that are found from tropics to boreal region and occupy from understory to arborescent strata. Phenology is an integrative environmental science that studies the vegetative and reproductive events of plants and their relation to the climate. Phenological studies with ferns have been carried out along Brazilian territory for about 36 years, with plants monitored mainly in the southern and northeastern regions of the country. Several approaches can be given to phenological monitoring, in order to understand the influence of climate on the triggers of phenophases, the growth and development of plants. Thus, through an extensive review in the scientific literature, this article aims to approach and to construe a Brazilian phenological scenario for the fern and lycophyte species monitored in the country. In addition, to compile the methodological approaches necessary to reach the phenological responses of these plants, as well as new research perspectives and to indicate gaps in the field of knowledge to be fulfilled.
\end{abstract}

Keywords: Climate, Phenophase, Monitoring.

\section{Introdução}

O que é fenologia?

Fenologia vem do grego phaino que significa "aparecer" e logos que significa "estudo". Por definição, fenologia é a observação do ciclo de vida das plantas e dos animais (Lieth, 1974) e a recorrência dos eventos biológicos em função das influências bióticas e abióticas, além das suas interrelações na população ou em comunidade (US/IBP
Phenology Committee, 1972). Carl Linneaus utilizou alguns aspectos do biorritmo das plantas para fabricar o chamado "floral clock". Para produzi-lo, o naturalista dividiu a observação da floração em três categorias: as que abriam e fechavam sob influência do clima, as que acompanhavam as mudanças de horas de luz (latitude) e as que abriam as flores somente em um 
período específico do dia repetindo sempre no mesmo intervalo de tempo.

A fenologia foi aplicada por muito tempo sem ser chamada dessa forma até que, quase um século mais tarde, em 1853, o termo "fenologia" foi criado pelo botânico Charles François Antoine Morren (Puppi, 2007). Aguardar e assistir todos os anos as cerejeiras florescerem é uma cultura tradicional no Japão e nada mais é que uma maneira de monitorar a fenologia de uma espécie.

O trevo de quatro-folhas, uma samambaia do gênero Marsilea, fecha suas folhas ao anoitecer, quando a radiação solar diminui e abre novamente ao amanhecer, em movimentos que chamamos de nictinásticos (Darwin, 1880).

\section{Samambaias e licófitas}

As samambaias e licófitas são semelhantes a todos os outros grupos que necessitam da energia solar para realizar fotossíntese, embora diferenciem-se no que diz respeito a estrutura (não possuem flores, frutos e nem sementes), ciclo de vida e seu modo de dispersão. Essas plantas são caracterizadas por alternarem duas gerações no seu ciclo de vida, a que produz os esporos e é mais longa (geração esporofítica) e a que produz os gametas, é de menor complexidade morfológica e é mais curta (geração gametofítica) (Zuquim et al., 2008; Sharpe et al., 2010).

$\mathrm{Na}$ maior parte das samambaias $\mathrm{o}$ crescimento das folhas ocorre quando existe o aumento do diâmetro do báculo (folhas jovens), o alongamento do pecíolo, o desenrolamento da raque e dos folíolos (Sharpe e Mehltreter, 2010). Por primeiro temos o surgimento do báculo, que dá origem a uma folha jovem, que por sua vez é estéril ou fértil; essa mesma folha alcança a maturidade e mantem a sua característica quanto à fertilidade; a folha adulta fértil passa pelo processo de maturação dos seus esporângios (responsáveis pela reprodução) desde a forma imatura até a completa liberação dos esporos. Após esse processo, mesmo que não necessariamente de modo concomitante, tanto a folha estéril quanto a fértil entram em senescência.

As samambaias e licófitas fazem parte do componente vegetativo de diversos ecossistemas ao redor do mundo. Distribuem-se desde os trópicos até a região boreal, ocupam o estrato herbáceo até o arborescente e ainda assim representam apenas 4\% das plantas vasculares (Sharpe et al., 2010). Até o momento, são reconhecidas 10.578 espécies de samambaias e 1.338 espécies de licófitas no mundo (PPG I, 2016). Um pouco mais de 220 espécies têm sido material de estudos fenológicos realizados no mundo e o interesse por esse tipo de pesquisa científica tem se intensificado gradualmente e atraído atenção de pesquisadores (Lee et al., 2018). No Brasil, estudos envolvendo fenologia de samambaias têm sido realizados há cerca de 36 anos, iniciando com estudo publicado de Windisch e Pereira-Noronha 1983.

Então, o que monitorar nas samambaias e licófitas? Os períodos vegetativos e reprodutivos das plantas compreendem etapas do ciclo de vida das folhas, que são chamadas de fenofases, e podem ser monitoradas por diferentes metodologias, fornecendo ao término do acompanhamento importantes considerações ecológicas sobre o desenvolvimento da espécie, da população ou da comunidade. De modo geral, podemos monitorar todo o ciclo de vida visível dessas plantas, desde a emergência até a morte das suas folhas. É importante que se monitore todo o ciclo vital para que com essas informações coletadas se tenha a taxa de renovação e senescência das folhas, além da capacidade e época de reprodução dessas plantas.

À procura dessas informações, uma revisão da literatura foi realizada para as espécies de samambaias monitoradas no Brasil. A pesquisa científica bibliográfica foi realizada utilizando os termos "fenologia" e "samambaias" nos bancos de dados da Scientific Eletronic Library OnLine (SciELO), Web of Science (WoS), Science Direct e Periódicos CAPES. As buscas restringiram-se em artigos publicados até agosto de 2019.

\section{Desenvolvimento}

\section{Metodologias}

A metodologia de escolha dos indivíduos para monitorar deve levar em consideração a sua forma de vida e a sua idade, sendo indispensável que sejam selecionadas plantas adultas para que se possa monitorar sua fenologia reprodutiva. Espécies epifíticas necessitam de um forófito (árvore) como suporte para crescer, e dessa maneira, deve-se definir primeiramente a árvore para depois selecionar o indivíduo. A escolha do forófito como a unidade amostral pode facilitar a definição de um método para escolher os indivíduos epifíticos que serão monitorados. Uma vez que as árvores em que se encontram as plantas epifíticas possuem diversas formas em sua estrutura de galhos e também idades variadas (Kersten e Waechter, 2011), alguns critérios de inclusão podem ser utilizados para selecionar o forófito conforme o objetivo do estudo. Os critérios 
podem ser o diâmetro da altura do peito (DAP) e a altura, que indiretamente caracterizam se uma árvore é de grande porte e se está presente há mais tempo no ambiente (mais velha). Essas características podem ser úteis para a seleção de epífitos que compõe uma comunidade porque, por exemplo, a riqueza será maior nessas condições. Além disso, selecionar árvores de espécies variadas (heterogeneidade do tipo de casca) podem contribuir para o incremento de espécies epifíticas na comunidade a ser monitorada. $\mathrm{O}$ posicionamento de um forófito dentro de um fragmento florestal também pode influenciar a fenologia e, se não for o objetivo, evitar a escolha de árvores que fiquem nas bordas dos ambientes auxilia na exclusão do efeito de borda.

Muitas vezes a observação de uma nova folha ou de um indivíduo fértil torna-se difícil em nível do solo e, para realizar com precisão, pode ser necessário o uso de escada ou até mesmo de material de escalada, visto que os indivíduos podem ser pequenos ou ficar em locais de difícil visibilidade, próximos à copa externa das árvores. $\mathrm{O}$ uso de binóculo pode se fazer necessário se nenhuma dessas maneiras for suficiente para observar o indivíduo. Uma maneira de realizar a fenologia mesmo sem o auxílio desse material é dividir a árvore em regiões fazendo uma estratificação vertical, que pode ser a divisão em intervalos regulares de altura, em zonas de altura (base, fuste, copa) ou zonas ecológicas (Johansson, 1974).

A dificuldade da individualização dos espécimes para serem monitorados vai depender principalmente da sua forma de vida. Algumas samambaias produzem assexuadamente de um único ancestral indivíduos geneticamente idênticos, formando um clone (genet). Neste caso, devemos escolher um membro desse clone (ramet) para realizar o monitoramento, evitando uma falsa homogeneidade no comportamento fenológico de uma população. Esse problema no momento da seleção pode ocorrer com algumas espécies fanerófitas, que aparentemente são fáceis de individualizar, porque podem alcançar mais de $6 \mathrm{~m}$ de altura, apresentam uma coroa de folhas no ápice de seus cáudices e pertencem ao componente arbustivo-arbóreo. A samambaia arborescente Alsophila setosa Kaulf é um exemplo típico desse tipo de reprodução e manifestação no ambiente natural, tendo seus cáudices próximos ligados por ramificações estoloníferas (Schmitt e Windisch, 2005; Schmitt e Windisch, 2006a). Já para plantas hemicriptófitas, que possuem as estruturas perenes semienterradas ou protegidas junto à superfície do solo, pode ser revelado níveis de dificuldade diferentes, sendo mais fáceis de selecionar as espécies rosuladas, como Asplenium claussenii Hieron. e Didymochlaena truncatula (Sw.) J. Sm. de que reptantes, tais como Rumohra adiantiformis (G. Forst.) Ching e Pteris deflexa Link. Nesse caso, o rizoma se prolonga sob a superfície do solo e pode alcançar alguns metros, dificultando a separação dos indivíduos, quando localizados próximos uns dos outros. Da mesma forma, isso ocorre para os epífitos, que podem ser rosulados, como Asplenium gastonis Feé e A. scandicinum Kaulf. ou reptantes como Microgramma squamulosa (Kaulf.) de la Sota e Pleopeltis pleopeltifolia (Raddi) Alston. Em muitos casos, para plantas reptantes é necessária uma pequena escavação do solo em torno dos indivíduos para que o observador consiga identificar o início e o final do rizoma, evitando que um mesmo indivíduo seja considerado dois e monitorado duplamente. De maneira geral, todos esses indivíduos podem ser incluídos na amostragem por meio de parcelas, transectos ou trilhas pré-estabelecidas em ambientes de interesse.

Independentemente da forma de vida das samambaias e licófitas é importante que os indivíduos sejam marcados e numerados com etiquetas plásticas ou fitas de demarcação de modo que possam ser reconhecidos durante o período de monitoramento. É imprescindível que o mesmo indivíduo seja monitorado durante todo o tempo de amostragem, para que se tenha repetidamente todas as informações, desde a emergência até a completa senescência foliar 


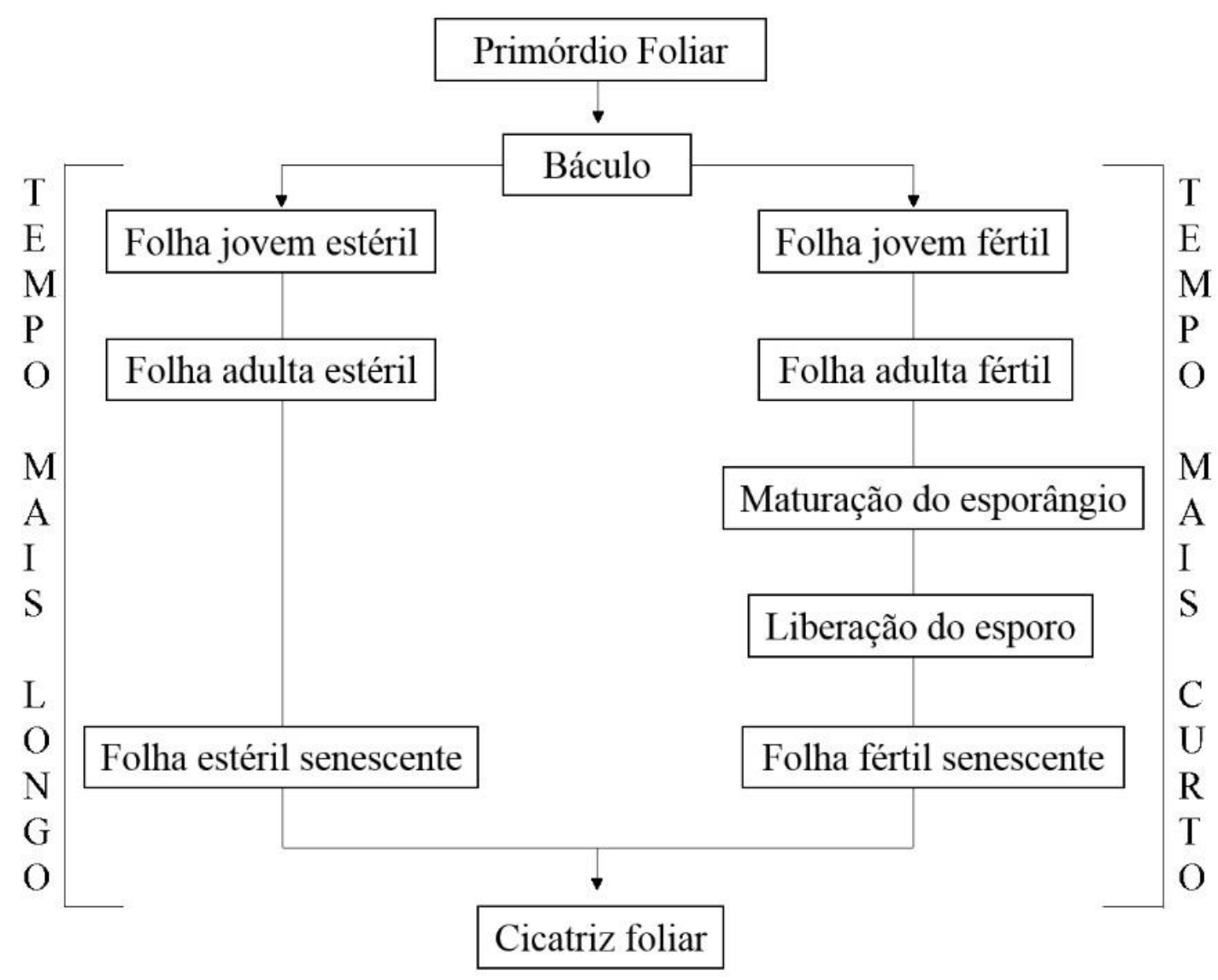

Figura 1. Esquema do ciclo de vida das folhas das samambaias. Adaptado de Sharpe e Mehltreter (2010).

A maioria dos estudos fenológicos no Brasil são realizados em nível populacional e poucos são em comunidade. Apenas um estudo realizado por Müller et al. 2019, monitorou e analisou uma comunidade de samambaias. Outros estudos realizados por Ranal 1995, Farias e Xavier (2011a) e Souza et al. 2013, contemplaram mais de uma espécie de samambaia no seu monitoramento, mas as análises dos resultados desses estudos não foram realizadas para a comunidade e sim para as espécies individualmente. Tanto os estudos de população quanto os de comunidade fornecem informações relevantes sobre a fenologia, embora os resultados obtidos em nível comunitário abordem uma visão mais ampla e fidedigna de como essas plantas respondem aos estímulos que recebem no ambiente em que estão inseridas.

Existem algumas metodologias que são utilizadas para outros grupos de plantas, como para as angiospermas, que também podem ser aplicadas para as samambaias e licófitas se respeitada as características biológicas desse grupo. O tempo de monitoramento das plantas precisa permitir que todo o ciclo biológico seja observado e, de preferência, repetidamente, o que pode variar muito entre as espécies, considerando as que tem ciclo subanual, anual e supra anual. A maior parte dos estudos envolvendo samambaias no Brasil, e até mesmo para o mundo, tem utilizado a contagem do número de folhas em determinada fenofase, obtendo mensalmente a média e o desvio padrão. Os autores têm separado as fenofases vegetativas e reprodutivas e, para cada uma delas, verificado o número de folhas em que ocorre a manifestação. Essa é uma abordagem metodológica classificada como quantitativa.

Também é possível aplicar o índice de intensidade proposto por Fournier 1974. As observações das fenofases tornam-se mais subjetivas, seguindo uma escala intervalar semiquantitativa de cinco categorias ( 0 - ausência da fenofase, $1-1$ a $25 \%, 2-26$ a $50 \%, 3-51$ a $75 \%$ e $4-76$ a $100 \%$ ) que permitem enquadrar cada indivíduo na proporção em que a fenofase está manifestando-se. A partir desses valores de 0 a 4 , faz-se a soma do valor que cada indivíduo recebeu e divide-se pelo valor máximo que a população ou comunidade poderia receber. Para saber esse valor máximo deve-se multiplicar o número de indivíduos por 4. Além dessas metodologias, podemos aplicar o índice de atividade que é uma mensuração qualitativa da proporção de indivíduos 
em cada fenofase por meio da sua presença ou a ausência, resultando em uma observação mais objetiva (Bencke e Morellato, 2002).

De maneira geral, existem algumas semelhanças e diferenças entres os métodos quali e quantitativos que podem ser fundamentais na escolha da maneira em que será realizada a fenologia para alcançar os objetivos de cada estudo. Considerando que a frequência mínima de monitoramento é uma vez ao mês e que se tem como sugestão o mínimo de 10 indivíduos selecionados para cada espécie, excetuando-se as espécies raras (Fournier e Charpantier, 1975), deve-se atentar para o tempo disponível do pesquisador para monitorá-los. A partir disso, o método qualitativo mostra-se mais rápido para ser realizado em campo do que os métodos quantitativos.

Os três tipos de metodologia permitem constatar o começo e o fim de um evento fenológico, mas apenas o método qualitativo deixa em evidência a sincronia da fenofase, que é quando todos os indivíduos apresentam a mesma fenofase em um mesmo período de tempo. É também somente esse método qualitativo que permite analisar os dados de herbário quanto a ocorrência de determinado evento fenológico em cada exsicata. No entanto, uma desvantagem é que essa análise qualitativa não evidencia os picos de intensidade dentro de uma população ou comunidade, sendo para isso necessário a aplicação dos métodos quantitativos (Bencke e Morellato, 2002), mais especificamente o índice de intensidade.

$\mathrm{O}$ método quantitativo torna-se uma análise mais refinada de como realmente é o desenvolvimento da planta durante o período de monitoramento. Essa observação mais aprofundada é importante porque mesmo que todos os indivíduos da população tenham folhas férteis, por exemplo, sabendo a intensidade em que isso acontece em cada indivíduo podemos avaliar o potencial ou a viabilidade de reprodução de determinada espécie ameaçada de extinção ou rara. Verificar que todos os indivíduos produzem e perdem suas folhas ao longo do tempo é uma característica mais geral de que determinar a quantidade de folhas que emergem e morrem, permitindo constatar se as plantas passam por algum período sem folhas, que por sua vez influenciaria diretamente na realização de fotossíntese.

Uma maneira de verificar a sazonalidade das fenofases é por meio de uma abordagem de estatística circular para a análise dos dados. Nos estudos fenológicos, a frequência relativa ou a intensidade de uma fenofase são agrupadas nos meses do ano correspondente em que ocorreram. Como os meses são um tipo de escala circular, pode-se convertê-los em ângulos, obtendo 12 intervalos de aproximadamente $30^{\circ}\left(360^{\circ}\right.$ de um círculo dividido por 12 meses do ano), em que cada dia do ano corresponde a $0,9836^{\circ}\left(360^{\circ}\right.$ dividido por 365 dias). Com isso, tem-se os dados fenológicos distribuídos nos seus respectivos ângulos, que após serem analisados, é possível verificar se os indivíduos apresentaram uma fenofase concentrada significativamente em uma data específica dentro de um período de tempo, demonstrando ou não a sazonalidade do evento fenológico. Conhecer as datas fenológicas revela importantes considerações ecológicas sobre as espécies e os ambientes (Morellato et al., 2010).

\section{Fenologia com samambaias e licófitas}

Diferente de outros grupos vegetais, as samambaias não dependem de interação com polinizadores ou dispersores para reproduzir, sendo o clima o principal regulador dos seus eventos fenológicos, como a fertilidade, a renovação e a senescência das folhas (Barrington, 1993). Com o clima definindo o período de ocorrência dessas fenofases temos a possibilidade do surgimento da sazonalidade, que é quando determinado evento fenológico aparece nos indivíduos de uma população ou comunidade e permanece por um período de tempo limitado e específico, não se apresentando de maneira recorrente ao longo de um ano (Lieth, 1974). Dessa maneira, o comportamento fenológico das samambaias e licófitas responde sazonalmente às condições climáticas do ambiente em que estão crescendo.

Para entender como essas plantas se desenvolvem no Brasil é necessário compreender rapidamente o clima do local onde elas foram monitoradas. Os estudos envolvendo fenologia de samambaias no país tem se distribuído principalmente entre as regiões sul e nordeste, com alguns trabalhos sendo desenvolvidos no sudeste e centro-oeste. A região sul (extremo sul) abriga 54\% dos trabalhos enquanto a nordeste $35 \%$, sendo os restantes $12 \%$ distribuídos no sudeste e centrooeste.

Essas duas regiões com maior número de monitoramentos possuem diferenças climáticas acentuadas, principalmente quanto à alternância de períodos secos e úmidos. A posição geográfica em que o Brasil se encontra, entre a linha do Equador e o Trópico de Capricórnio, abrange uma grande variedade de climas e a maior parte do seu território 
localiza-se dentro da zona intertropical, enquanto uma menor área encontra-se na zona subtropical. Existe um gradiente latitudinal a partir do Equador em direção ao sul que ocasiona variações em fatores climáticos e astronômicos, resultando em uma transição do clima tropical para subtropical (Marques, 2007). O clima subtropical, que caracteriza o sul do Brasil, é considerado o mais regular do Brasil com chuvas distribuídas ao longo de todos os meses. O clima da região nordeste apresenta uma heterogeneidade das chuvas no tempo e no espaço (Vianello e Alves, 2012), ocorrendo assim estação seca e úmida.

A partir dessas diferenças climáticas esperava-se que a precipitação fosse $o$ fator determinante para a ocorrência da sazonalidade nas fenofases, e que, em regiões sem grandes mudanças no volume das chuvas ao longo do ano, não ocorreriam variações sazonais. $\mathrm{O}$ que pode-se observar nos estudos realizados para o Brasil é que para algumas espécies esse é o padrão observado. Ao contrário, algumas samambaias podem não demonstrar sazonalidade para algum evento fenológico mesmo quando localizadas em ambientes sazonais para a precipitação. Além disso, outras espécies podem apresentar sazonalidade mesmo em ambientes não sazonais, como podemos observar na Tabela 1 .

Essa sazonalidade das fenofases que as plantas apresentam também pode ser uma estratégia para o escape da herbivoria. Uma planta que renova suas folhas ao longo de todo o ano possivelmente torna menor a predação em excesso das folhas de um único indivíduo (Morellato et al., 1989) do que plantas que renovam suas folhas somente uma ou duas vezes ao ano. A sazonalidade do clima também regula a ocorrência de predadores, podendo ser menor na estação seca (Coley e Barone, 1996), ou haver uma sincronia entre seus ciclos de vida com os picos de produção de folha (Frankie et al., 1974). A espécie Blechnum serrulatum Rich monitorada em ambiente com alternância climática não apresentou mecanismos de defesa contra herbívoros satisfatórios uma vez que apresentou folhas predadas ao longo de todo o ano (Faras e Xavier, 2013a). Já os indivíduos de Phlebodium decumanum (Willd.) J.Sm. foram predados na estação chuvosa, momento em que ocorreu o pico de folhas férteis e os recursos estavam disponíveis aos herbívoros (Farias e Xavier, 2013b). Entretanto, para Thelypteris interrupta (Willd.) K. Iwats. monitorada em ambiente com período seco e chuvoso, não houve sazonalidade nem nos eventos fenológicos e nem na herbivoria foliar dessas plantas (Farias e Xavier, 2011b).

Tabela 1. Espécies de samambaias estudadas em ambientes sazonais (S) e não sazonais (NS) para a precipitação. ${ }^{1}$ Schmitt e Windisch (2006a), ${ }^{2}$ Schmitt et al. (2009), Farias e Xavier (2011a) ${ }^{3}$ e Farias et al. $(2015)^{4}$.

\begin{tabular}{cccccc} 
& & & \multicolumn{3}{c}{ Eventos fenológicos } \\
\cline { 3 - 6 } & \multirow{2}{*}{ Região } & Espécie & Renovação & Fertilidade & Senescência \\
\cline { 3 - 6 } Não sazonal & \multirow{2}{*}{ Sul } & Alsophila setosa $^{1}$ & S & NS & S \\
\cline { 3 - 6 } \multirow{2}{*}{ Sazonal } & \multirow{2}{*}{ Nordeste } & Dicksonia sellowiana $^{2}$ & NS & S & NS \\
\cline { 3 - 6 } & & Acrostichum danaeifolium $^{3}$ & NS & NS & NS \\
\cline { 3 - 6 } & & Didymochlaena truncatula & NS & NS & NS \\
\hline
\end{tabular}

A produção e senescência foliar para muitas samambaias pode ser estimulada pela precipitação (Tabela 2), principalmente nas regiões onde existem alternância entre o período seco e úmido, devido ao sistema radicular pequeno das plantas que pode dificultar o acesso à água durante a estação menos chuvosa (Mehltreter, 2006). Por outro lado, nas áreas de maior latitude, que apresentam regime anual regular de chuvas, a disponibilidade de água pode não ser um fator limitante para as samambaias e o gatilho para a produção de novas folhas pode estar sendo outras variáveis como a temperatura e o fotoperíodo, que possuem maior amplitude ao longo dos meses

Müller.A; Schmitt.J.L. nesse local (Tab. 2). Se as fenofases vegetativas apresentarem-se como um evento contínuo ao longo de um ano, por exemplo, a dependência das chuvas torna-se menor (Seghieri et al., 1995). O hábitat em que uma samambaia está inserida também pode exercer mais influência nas respostas fenológicas de que a própria sazonalidade da chuva, como o observado para Acrostichum danaefolium, crescendo em um mangue no Golfo do México que propiciou a umidade do solo necessária para o surgimento de folhas em um padrão não sazonal independente da sazonalidade da chuva (Mehltreter e Palacios-Rios, 2003). 
A sazonalidade da fertilidade das samambaias pode estar associada às diferenças entre espécies dimórficas e monomórficas (Mehltreter e Palacios-Rios, 2003). As plantas que tem o dimorfismo foliar como característica possuem folhas férteis diferenciadas que permanecem na planta por um curto período de tempo. Essas folhas entram em processo de senescência logo após a liberação dos seus esporos. Ao contrário, as plantas monomórficas não possuem essa especialização nas suas folhas férteis sendo iguais às estéreis. As folhas férteis podem continuar vivas por um período maior de tempo, por acumular duas funções, a de reprodução e a de realizar fotossíntese (Lee et al., 2009). Com isso, existe uma tendência das espécies dimórficas terem um comportamento mais sazonal de que as monomórficas (Mehltreter e Palacios-Rios, 2003), como o observado na samambaia herbácea Danaea geniculata Raddi. (Farias et al., 2018).

Por outro lado, no Brasil, espécies monomórficas como Microgramma lindbergii, Adiantopsis radiata (Ranal, 1995) e Dicksonia sellowiana (Schmitt et al., 2009) apresentaram a fertilidade sazonal assim como as espécies dimórficas Microgramma squamulosa (Ranal,
1995) e Anemia tomentosa (Sav.) Sw. var. anthriscifolia (Schrad.) Mickel (Souza et al., 2007). Esses exemplos demonstram que outros fatores além do dimorfismo foliar podem estar desencadeando a manifestação da fertilidade de samambaias, tais como as condições meteorológicas (Souza et al., 2007; Schmitt et al., 2009) e o fotoperíodo (Schmitt et al., 2009).

Além disso, esse comportamento da fertilidade de samambaias pode refletir na sazonalidade da senescência das folhas porque espera-se que, quando analisadas em nível populacional, as espécies dimórficas tenham maior concentração de folhas mortas de que as monomórficas. Em nível de comunidade, pode ocorrer uma heterogeneidade maior do comportamento das espécies com essa fenofase, em que a morte das folhas pode se distribuir mais regularmente ao longo do tempo evidenciando um comportamento não sazonal, devido à presença de plantas dimórficas e monomórficas. Ainda, não podemos deixar de levar em consideração os reguladores internos das plantas, como os hormônios, que podem ter influência do ciclo de vida da folha (Sharpe e Mehltreter, 2010).

Tabela 2. Influência da temperatura (T), do fotoperíodo (F) e da precipitação (P) nos eventos fenológicos de samambaias da região sul e nordeste do Brasil. + para relações positivas e - para relações negativas. ${ }^{1}$ Neumann et al. (2014), ${ }^{2}$ Müller et al. (2016), ${ }^{3}$ Souza et al. (2013).

\begin{tabular}{|c|c|c|c|c|}
\hline \multirow[b]{2}{*}{ Região } & \multirow[b]{2}{*}{ Espécie } & \multicolumn{3}{|c|}{ Eventos fenológicos } \\
\hline & & Renovação & Fertilidade & Senescência \\
\hline \multirow{2}{*}{ Sul } & Cyathea corcovadensis 1 & $\mathrm{~T}+\mathrm{F}+$ & $\mathrm{T}+$ & $\mathrm{T}+$ \\
\hline & Lindsaea lancea ${ }^{2}$ & $\mathrm{~T}+\mathrm{F}+$ & $\mathrm{T}+\mathrm{F}+$ & $\mathrm{T}+\mathrm{F}+$ \\
\hline \multirow{2}{*}{ Nordeste } & Adiantum deflectens $^{3}$ & $\mathrm{P}+$ & & $\mathrm{P}-$ \\
\hline & Adiantum petiolatum $^{3}$ & $\mathrm{P}+$ & $\mathrm{T}+$ & \\
\hline
\end{tabular}

\section{Classificação das fenofases}

Para classificar as fenofases das samambaias e licófitas, a partir de um ano de observação, nós propomos as categorias contínua, descontínua, regular e irregular (Müller et al., 2019) que seguem descritas e exemplificadas abaixo:

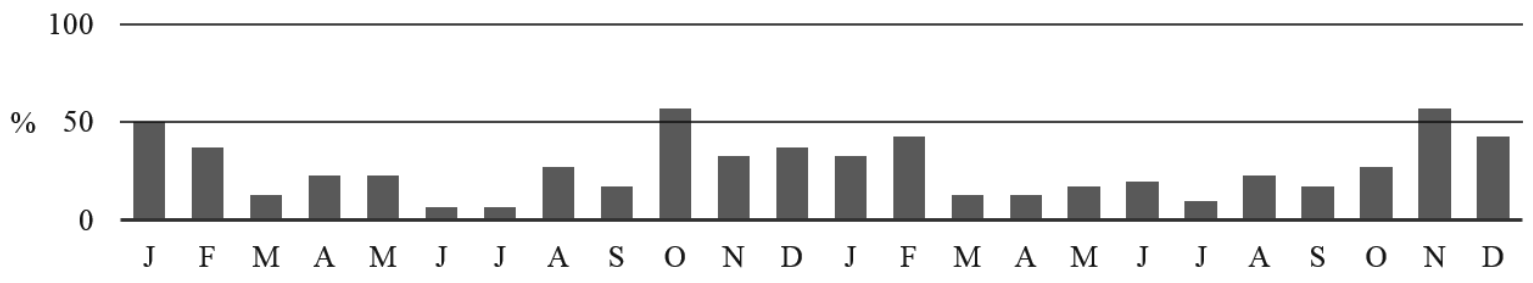

Figura 2. Fenofase contínua de Lindsaea lancea.
I) Fenofases contínuas: são aquelas que apresentam frequência de indivíduos ou média de folhas ocorrendo em todos os meses de observação em pelo menos um indivíduo da população ou da comunidade. Exemplo: renovação foliar de Lindsaea lancea (Müller et al., 2016) (Figura 2).

Müller.A; Schmitt.J.L. 
I) Fenofases descontínuas: são aquelas que apresentam frequência de indivíduos ou média de folhas com uma interrupção ao longo das observações, com pausa de, no mínimo, um mês. Exemplo: esporângios em formação de Lindsaea lancea (Müller et al., 2016) (Figura 3).

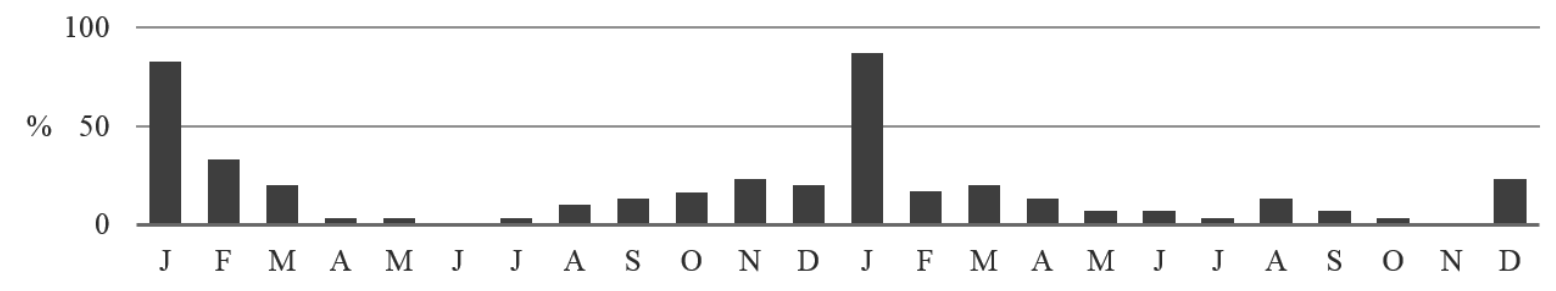

Figura 3. Fenofase descontínua de Lindsaea lancea.

II) Fenofases regulares: são aquelas que apresentam frequência de indivíduos ou média de folhas com pouca variação ao longo das observações, em que os picos das manifestações da fenofase oscilam em frequências próximas 100

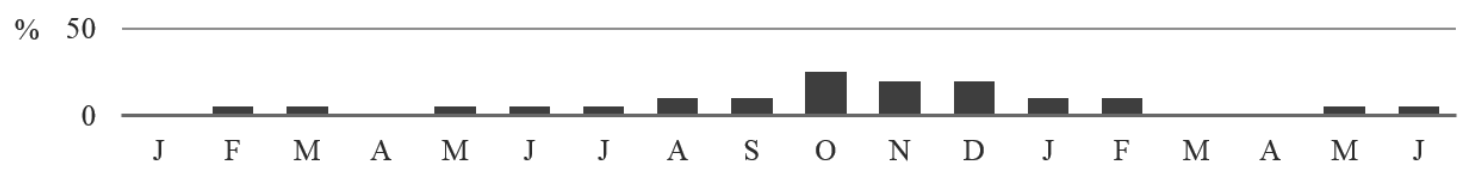

Figura 4. Fenofase regular de Blechnum acutum.

III) Fenofases irregulares: são aquelas que apresentam frequência de indivíduos ou média de folhas com expressiva variação ao longo das observações, em que os picos das manifestações da fenofase oscilam em frequências distantes

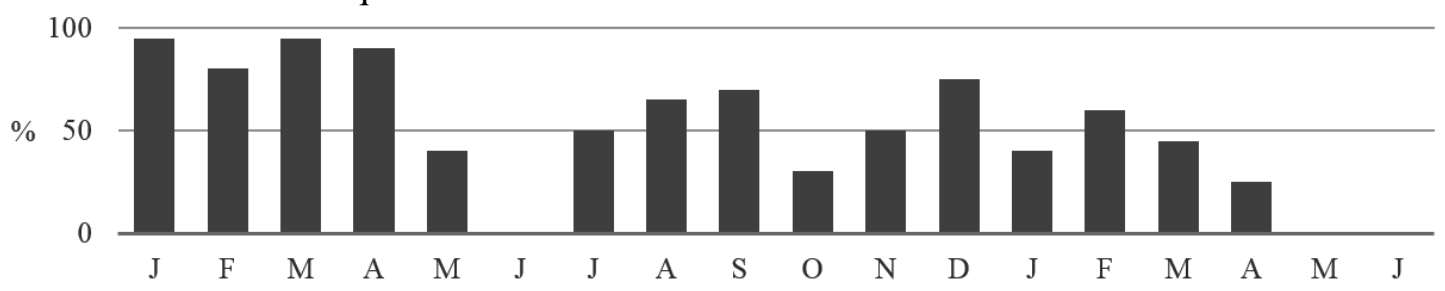

Figura 5. Fenofase irregular de Blechnum acutum.

As fenofases das samambaias monitoradas no Brasil demonstram uma tendência de serem mais descontínuas (66\% das fenofases) do que contínuas e de serem mais irregulares $(88 \%$ das fenofases) do que regulares (Müller et al., 2019). As fenofases vegetativas, em sua grande maioria, são irregulares e, as reprodutivas, oscilam de acordo com o detalhamento em que são observadas (folhas férteis, esporângios em formação ou imaturos, fechados ou liberando esporos) podendo se apresentarem como regulares ou irregulares. Dessa maneira, existe uma maior probabilidade de se observar e classificar as fenofases em Müller.A; Schmitt.J.L. (variação maior do que 30\%) (Müller et al., 2019). Exemplo: renovação foliar de Blechnum acutum (Padoin et al., 2016) (Figura 5). (variação de até 30\%) (Müller et al., 2019). Exemplo: formação de esporângios de Blechnum acutum (Padoin et al., 2016) (Figura 4). descontínuas e irregulares. No entanto, existem outros tipos de classificação e tanto um evento fenológico contínuo quanto um descontínuo pode ser regular ou irregular. A renovação foliar de

Lindsaea lancea foi contínua e irregular (Figura 2) e a formação de esporângios de Blechnum acutum foi descontínuo e regular (Figura 4).

\section{Expansão foliar}

Para monitorar e medir o quanto a folha aumenta em comprimento é necessário a 
observação desde a emergência do báculo até a sua completa expansão. Para isso, primeiro deve-se esperar o surgimento de um báculo (nova folha) e, nesse momento, marcá-lo com algum material que o identifique e o diferencie das demais folhas na planta, como um atílio ou uma etiqueta plástica, por exemplo. Após realizada essa marcação é preciso monitorá-lo ao longo de dias ou meses até que ele tenha se desenrolado completamente. Durante esse processo deve-se medir periodicamente o comprimento dessa nova folha a cada observação.

Essa também é uma maneira de observar as plantas. A expansão foliar pode ser acompanhada porque ocorre da seguinte maneira: os báculos, ápices circinados jovens não expandidos, ficam completamente enrolados em sua base e próximos ao rizoma. Lentamente, à medida em que vão expandindo, desenrolam-se em espiral e, por fim, apresentam-se no formato da folha (Figura 6). Essa maneira de desenrolar é consequência da expansão desigual da folha, cuja as células da face abaxial (outer surface) alongam-se mais do que as da face adaxial (inner surface), ficando totalmente estendida quando o crescimento das duas faces se igualam (Moran, 2004).
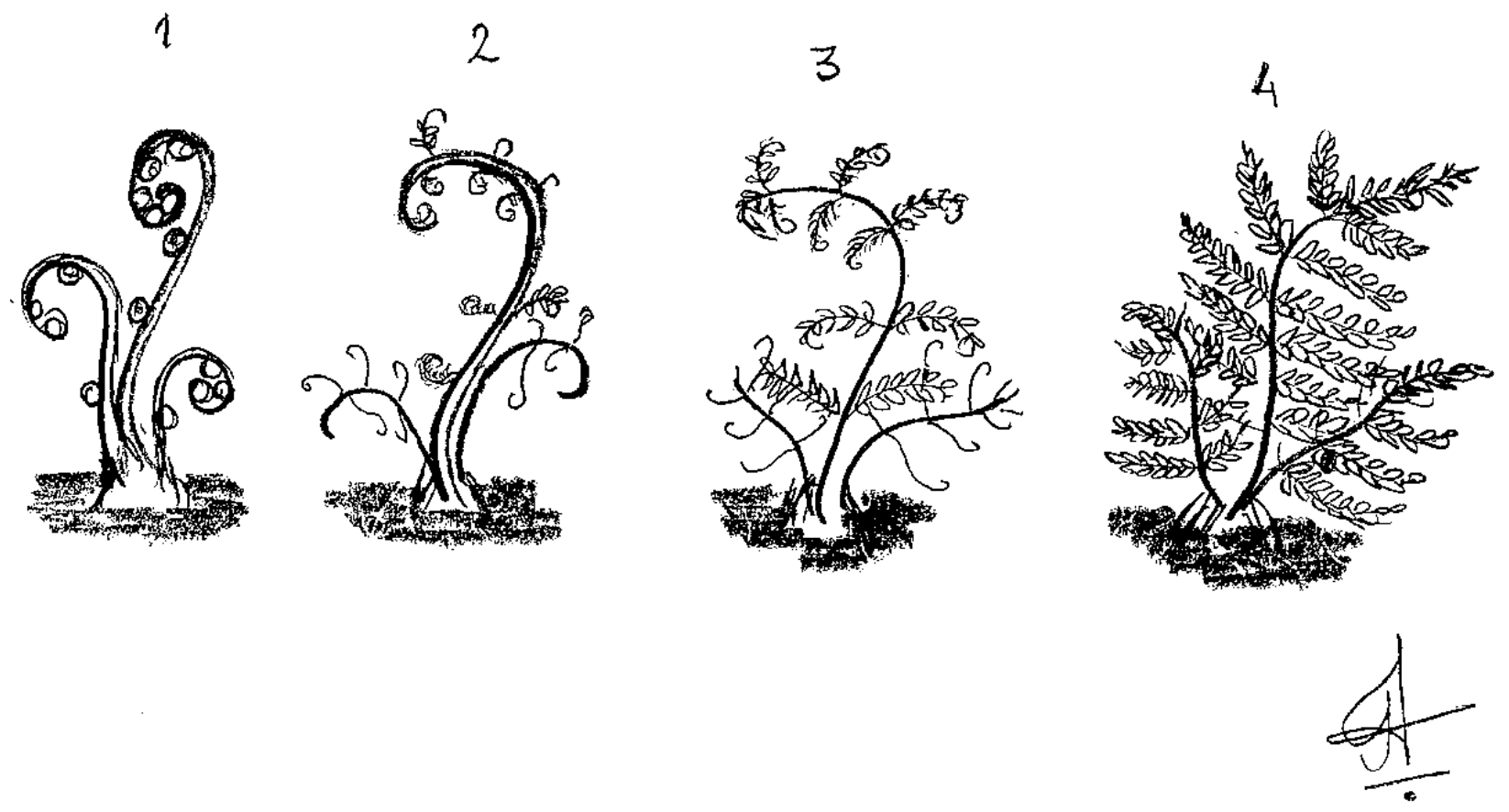

Figura 6. Etapas do desenrolar do báculo.

O tempo de duração da expansão foliar tem relação com várias características ambientais e das próprias plantas que podem se manifestar isoladamente ou de forma combinada (Kikuzawa e Lechowicz, 2011). A partir disso, deve se levar em consideração o tempo de permanência das folhas nas plantas nas diferentes regiões climáticas do Brasil. As samambaias de ambientes tropicais tendem a apresentar uma maior persistência das folhas na planta devido ao clima quente e úmido que favorece a característica perene. Já as folhas das samambaias que ocorrem nas regiões subtropicais e nas regiões com alternância entre períodos secos e chuvosos podem comportar-se de forma semelhante às de regiões temperadas, estando expostas a estressores ambientais como o frio ou a seca desencadeando a sua senescência e o término do seu ciclo de vida (Mehltreter e Sharpe, 2013).

Müller.A; Schmitt.J.L.
A rapidez em que a expansão foliar ocorre oscila entre as espécies e os locais em que as plantas estão crescendo. O estágio sucessional em que as plantas estão se desenvolvendo e sua consequente disponibilidade de luz podem desencadear respostas diferentes de crescimento da folha. Plantas expostas a locais mais abertos podem apresentar uma expansão mais rápida. No Brasil, Didymochlaena truncatula, crescendo no nordeste do país expandiu no primeiro mês $1,31 \mathrm{~cm} \mathrm{dia}^{-1}$ (Farias et al., 2015) e Rumohra adiantiformis na região sul expandiu até $1,39 \mathrm{~cm} \mathrm{dia}^{-1}$ (Lehn et al., 2002). As espécies arborescentes já monitoradas parecem manter um padrão de crescimento similar nos três primeiros meses (Tabela 3). Normalmente, o que se observa para essas samambaias é que o primeiro mês apresenta o maior aumento, seguido do segundo e terceiro mês, com uma diminuição da expansão gradativamente. 
Das espécies arborescentes monitoradas, existe um decréscimo médio do primeiro para o segundo mês de $2 \mathrm{~cm} \mathrm{dia}^{-1}$ e do segundo para o terceiro mês de mais $1,5 \mathrm{~cm} \mathrm{dia}^{-1}$, em média.

Tabela 3. Expansão foliar de samambaias arborescentes nos três primeiros meses monitorados, crescimento do cáudice e estimativa de idade para um cáudice de 1 metro de altura. ${ }^{1}$ Schmitt e Windisch (2006b), ${ }^{2}$ Schmitt e Windisch (2012), ${ }^{3}$ Neumann et al. (2014), ${ }^{4}$ Schmitt e Windisch (2007), ${ }^{5}$ Schmitt et al. (2009) ${ }^{6}$ Silva et al., (2019).

\begin{tabular}{|c|c|c|c|c|c|}
\hline \multirow{2}{*}{ Espécie } & \multicolumn{3}{|c|}{ Expansão foliar (cm dia-1) } & \multirow{2}{*}{$\begin{array}{l}\text { Crescimento do } \\
\text { cáudice }(\mathrm{cm} \text { ano-1) }\end{array}$} & \multirow{2}{*}{$\begin{array}{l}\text { Estimativa de idade } \\
\text { (cáudice 1m) }\end{array}$} \\
\hline & $1^{\circ}$ mês & $2^{\circ}$ mês & $3^{\circ}$ mês & & \\
\hline Alsophila setosa ${ }^{1}$ & 5,38 & 1,24 & 0,09 & 6,32 & 16 anos \\
\hline Cyathea atrovirens ${ }^{2}$ & 2,53 & 1,5 & 0,29 & 1,73 & 58 anos \\
\hline Cyathea corcovadensis ${ }^{3}$ & 4,13 & 2,69 & 1,62 & 6,63 & 15 anos \\
\hline Cyathea delgadii & 3,13 & 1,14 & 0,14 & 4,65 & 22 anos \\
\hline Dicksonia sellowiana ${ }^{5}$ & 3,45 & 3,31 & 0,28 & 4,78 & 21 anos \\
\hline Cyathea praecincta ${ }^{6}$ & 5,4 & 2,17 & 0,39 & - & - \\
\hline
\end{tabular}

\section{Crescimento do cáudice}

Estimar o quanto as plantas crescem em um determinado período de tempo também é uma maneira de monitorar o seu desenvolvimento. Apesar de apresentarem somente tecidos primários e condução de água por traqueídes, pode-se encontrar samambaias arborescentes com tamanhos variados em um sub-bosque, sendo que algumas podem alcançar até mesmo o dossel da floresta (Schmitt e Windisch, 2006a). O crescimento do cáudice nas samambaias arborescentes comporta-se da mesma maneira do crescimento das folhas, existindo uma grande variação interespecífica e em função das variações das condições ambientais de cada local em que estão inseridas (Tabela 2). Há uma tendência de espécies de florestas secundárias crescerem em média três vezes mais de que espécies localizadas em florestas primárias, como por exemplo Cyathea delgadii Sternb., que também ocorre em território brasileiro e cresceu $21,3 \mathrm{~cm}$ por ano em floresta primária e $81,9 \mathrm{~cm}$ por ano em floresta secundária na Costa Rica (Bittner e Breckle, 1995). No sul do Brasil, essa mesma espécie cresceu 4,65 $\mathrm{cm}$ por ano (Tabela 2) (Schmitt e Windisch, 2007). Cyathea atrovirens monitorada em dois locais no sul do Brasil cresceu cerca de três vezes mais em local aberto (Lehn e Leuchtenberger, 2008) do que em floresta secundária (Schmitt e Windisch, 2012). Essa diferença entre o crescimento de hábitats distintos pode estar relacionada a uma pressão competitiva entre as espécies, que é maior nos tipos florestais secundários e fazem com que essas plantas sejam estimuladas a crescer mais rapidamente. Associado a isso, o fato de uma planta crescer em hábitat secundário possibilita a mesma receber maior intensidade de luz penetrante devido a descaracterização da formação vegetacional original na qual está inserida. A altura da planta também pode afetar o seu próprio crescimento, pois se ela está localizada no interior florestal, quanto menor for a sua altura, menor será sua capacidade de interceptar luz (Mehltreter e García-Franco, 2008). A fenologia de três espécies no sul do Brasil corroborou essas informações, uma vez que os indivíduos mais altos de Cyathea delgadii apresentaram o maior crescimento do cáudice (Schmitt e Windisch, 2007) assim como os de Blechnum brasiliense Desv. (Franz e Schmitt, 2005) e indivíduos mais altos de Alsophila setosa produziram mais folhas (Schmitt et al., 2003). Cyathea delgadii também apresentou o mesmo comportamento de indivíduos mais altos produzirem mais folhas no centro-oeste do país (Lehn e Resende, 2007).

\section{Estimativa de idade}

O conhecimento sobre a idade de uma samambaia pode indiretamente revelar o tempo de um fragmento florestal, e associada à outras técnicas, torna-se uma ferramenta para obter informações sobre o remanescente no qual ocorre. Então, como descobrir há quanto tempo uma samambaia arborescente está presente em uma floresta? Como saber quanto tempo uma planta de 4 metros de altura leva para atingir esse tamanho? Existem duas formas de estimar a idade dessas plantas.

A primeira delas é uma estimativa em relação ao comprimento total do cáudice e o quanto 
em média ele cresceu em altura durante um ano. Para conseguir estabelecer essa razão é necessário um monitoramento anual das plantas. A segunda maneira de estimar a idade é a partir do número total de folhas já formadas por aquele indivíduo em relação à média de produção de folhas ao longo de um ano. Para saber a quantidade de folhas que um indivíduo já produziu durante toda sua vida é necessário realizar uma contagem dos vestígios ou cicatrizes foliares presentes no seu cáudice. Enquanto se realiza a contagem pode-se marcar a cicatriz foliar de alguma forma para que ela não seja recontada. Muitos cáudices podem ficar cobertos por raízes adventícias e por plantas epifíticas, o que pode dificultar a identificação das cicatrizes foliares durante a contagem, sendo necessário excluir os indivíduos com essa característica da amostra.

Embora essas sejam maneiras de estimar a idade de uma planta, o valor não é exato. Um dos motivos da estimativa ser uma aproximação da idade é a falta de conhecimento que se tem sobre o tempo em que determinada samambaia gasta entre o estabelecimento do esporófito e a formação de um cáudice que apresente as cicatrizes foliares que surgem e aparecem com a renovação foliar ao longo da sua vida. Outro fator que influencia na estimativa de idade é a origem reprodutiva das plantas, que pode apresentar desenvolvimento mais rápido se for formada de maneira assexuada do que as de origem sexuada (Schmitt e Windisch, 2006a).

Além disso, o crescimento total do cáudice durante o ano aumenta na mesma proporção do espaçamento foliar, que por sua vez está relacionado ao maior alongamento da base das folhas e o distanciamento entre elas (Ash, 1987). À medida em que as plantas se desenvolvem e ficam mais altas, podem apresentar folhas maiores, por terem cáudices mais desenvolvidos e poderem suportar maior massa foliar (Schmitt e Windisch, 2007). E quando essas plantas alcançam maiores alturas elas possuem uma tendência a produzirem mais folhas, como é o caso da Alsophila setosa estudada no sul do Brasil, que demonstrou essa relação entre a altura e a produção de folhas quando seus cáudices iguais ou maiores de 1,44 m produziram mais folhas que seus cáudices de no máximo $43 \mathrm{~cm}$ (Schmitt e Windisch, 2006a). Uma possível explicação para isso, que não ocorre somente com a produção de folhas, mas também com a fertilidade e com a senescência, seria que as plantas maiores possuem maior capacidade de interceptar luz no sub-bosque, desenvolvendo mais folhas e sendo mais produtivas (Schmitt e Windisch, 2007).
A idade de uma planta de 4 metros de altura, por exemplo, pode ser estimada em 34 anos por meio do método das cicatrizes foliares e 63 anos pelo método da proporção entre o crescimento total e anual do cáudice, como foi demonstrado para Alsophila setosa. Para esse estudo a estimativa de idade mais realística foi a de 34 anos, porque o registro fotográfico pretérito para o fragmento em que essas plantas estavam crescendo indicou que ele possuía aproximadamente 43 anos (Schmitt e Windisch, 2006a).

\section{Considerações finais}

Diante dessas informações sobre o que é a fenologia, de que maneira ela pode ser estudada e as informações que são possíveis conhecer por meio dela, podemos compreender a importância dessa área dentro da ecologia. Associado a isso, algumas metas podem ser realizadas para ampliar o conhecimento como:

(1) Realizar o estudo fenológico também em laboratório;

Se tivermos uma população crescendo em ambiente com temperatura e fotoperíodo controlados podemos separar a influência dessas duas variáveis na fenologia das plantas. Em ambiente natural não é possível distinguir qual das duas variáveis está influenciando mais diretamente a fenologia das plantas, devido a auto correlação que existe entre ambas.

(2) Conhecer o tempo gasto entre o estabelecimento do esporófito a partir do gametófito;

Quando se estima a idade de uma samambaia está se levando em consideração apenas o que pode ser contado em campo durante seu ciclo visível de vida. Sabendo-se quanto tempo a planta gasta entre a dispersão, a germinação de um esporo, formação do gametófito e estabelecimento do esporófito, pode-se ter mais precisamente há quantos anos a planta se desenvolve em um ambiente.

(3) Monitorar a fenologia das samambaias e licófitas a longo prazo;

Obter um banco de dados com informações fenológicas e climáticas durante vários anos é fundamental para compreender como as pequenas alterações climáticas afetam a fenologia, principalmente para esse grupo de plantas perenes de relativa vida longa, que são sensíveis e têm respondido de forma efetiva aos estímulos ambientais. 
(4) Explorar as respostas fenológicas das comunidades de samambaias;

Considerando que no Brasil existem 1360 espécies de samambaias e licófitas (Flora do Brasil, 2020), apenas cerca de $2 \%$ delas apresentam informações fenológicas em nível populacional publicadas. Adicionalmente, o estudo da fenologia de comunidades deve ser estimulado, principalmente pela resposta que essas plantas em conjunto podem revelar em relação a diferentes fatores ambientais (Müller et al., 2019). Novos estudos têm focado o grande potencial da fenologia no contexto de fragmentação e mudanças climáticas (Morelatto et al., 2013), sendo que samambaias e licófitas são especialmente favoráveis para a realização dos mesmos, porque, de modo geral, são mais sensíveis às variações de clima.

\section{Agradecimentos}

À Universidade Feevale pela infraestrutura. À Coordenação de Aperfeiçoamento de Pessoal de Nível Superior (CAPES) pela concessão de bolsa a primeira autora e ao Conselho Nacional de Pesquisa (CNPq) pela concessão de bolsa produtividade (PQ 308926/2017-0) ao segundo autor. Ao biólogo Fernando Bertoldi de Oliveira pelo desenho da figura 6 .

\section{Referências}

Ash, J., 1987. Demography of Cyathea hornei (Cyatheaceae), a tropical tree-fern from Fiji. Australian Journal of Botany 35, 331-342. https://doi.org/10.1071/BT9870331

Barrington, D.S., 1993. Ecological and historical factors in fern biogeography. Journal of Biogeography 20, 275-280. https://doi.org/10.2307/2845635

Bencke, C.C., Morellato, L.P.C., 2002. Estudo comparativo da fenologia de nove espécies arbóreas em três tipos de floresta atlântica no sudeste do Brasil. Revista Brasileira de Botânica, 25, 237-248.

Bittner, J., Breckle, S.W., 1995. The growth rate and age of tree fern trunks in relation to habitats. American Fern Journal 85, 37-42.

Coley, P.D., Barone, J.A., 1996. Herbivory and plant defenses in tropical forests. Annual Review of Ecology and Systematics 27, 305335.

https://doi.org/10.1146/annurev.ecolsys.27.1.3 05

Darwin, C., 1880. Modified circumnutation: sleep or nyctitropic movements, their use: sleep of cotyledons, in: Darwin, C. The Power of
Movement in Plants. Ed. John Murray 1 ed., London, pp. 120-136.

Farias, R.P., Costa, L.E.N., Barros, I.C.L., Mehlreter, K., 2018. Leaf phenology of Danaea geniculata (Marattiaceae) in a Submontane Tropical Forest, Brazil. American Fern Journal 108 (2), 35-46. https://doi.org/10.1640/00028444-108.2.35

Farias, R.P., Costa, L.E.N., Silva, I.A.A., Barros, I.C.L., 2015. Phenological studies of selected leaf and plant traits of Didymochlaena truncatula (Dryopteridaceae) in a Brazilian submontane tropical rainforest. Nordic Journal of Botany 33, 249-255. https://doi.org/10.1111/njb.00656

Farias, R.P., Xavier, S.R.S., 2011a. Fenologia e sobrevivência de três populações de samambaias em remanescente de Floresta Atlântica Nordestina, Paraíba, Brasil. Biotemas 24 (2), 13-20. https://doi.org/10.5007/2175$7925.2011 \mathrm{v} 24 \mathrm{n} 2 \mathrm{p} 13$

Farias, R.P., Xavier, S.R.S., 2011b. Aspectos fenológicos de Thelypteris interrupta (Willd.) K. Iwats. (Thelypteridaceae) na Floresta Atlântica Nordestina, Paraíba, Brasil. Biotemas 24 (2), 9196.https://doi.org/10.5007/21757925.2011v24n $2 \mathrm{p} 91$

Farias, R.P., Xavier, S.R.S., 2013a. Fenologia foliar de Blechnum serrulatum Rich. (Blechnaceae) em remanescente de Floresta Atlântica no estado da Paraíba, Brasil. Pesquisas, Botânica 64, 297-306.

Farias, R.P., Xavier, S.R.S., 2013b. Aspectos fenológicos de Phlebodium decumanum (Willd.) J.SM. (Polypodiaceae) em um fragmento urbano de Floresta Atlântica no estado da Paraíba. Revista Nordestina de Biologia 21, 71-78.

Flora do Brasil, 2020. Samambaias e Licófitas, in: Flora do Brasil 2020 em construção. Jardim Botânico do Rio de Janeiro [online]. Disponível:

<http://reflora.jbrj.gov.br/reflora/floradobrasil/ FB128483>. Acesso: 17 jul. 2019.

Fournier, L.A., 1974. Un metodo cuantitativo para la medición de caracteristicas fenológicas en arboles. Turrialba 24, 422-423.

Fournier, L.A., Charpantier, C., 1975. El tamaño de la muestra y la frequencia de las observaciones en el estudio de las caracteristicas fenológicas de los arbores tropicales. Turrialba 25, 45-48.

Frankie, G.W., Baker, H., Opler, P.A., 1974. Comparative phenological studies of trees in tropical wet and dry forests in the lowlands of Costa Rica. Journal of Ecology 62, 81-919. 
Franz, I., Schmitt, J.L., 2005. Blechnum brasiliense Desv. (Pteridophyta, Blechnaceae): estrutura populacional e desenvolvimento da fase esporofítica. Pesquisas, Botânica 56, 173-184.

Johansson, D.R., 1974. Ecology of vascular epiphytes in West African rain forest. Acta Phytogeographyca Suecica 59, 1-136.

Kersten, R.A., Waechter, J.L., 2011. Métodos quantitativos no estudo de comunidades epifíticas, in: Felfili-Fagg, J.M., Eisenlohr, P.V., Melo, M.M.R.F., Andrade, L.A., Meira Neto, J.A.A. (Eds.). Fitossociologia no Brasil: métodos e estudos de caso. Viçosa, Editora UFV, pp. 231-254.

Kikuzawa, K., Lechowicz, M.J., 2011. Leaves: Evolution, Ontogeny, and Death, in: Kikuzawa, K.; Lechowicz, M.J. Ecology of Leaf Longevity. Ecological Research Monographs, Springer, pp. 7-21.

Lee, P.H., Huang, Y.M., Chiou, W.L., 2018. Fern Phenology, in: Fernández, H. (ed.) Current Advances in Fern Research. Springer, Cham, pp. 381-399. https://doi.org/10.1007/978-3319-75103-0_18

Lee, P.H., Lin, T.T., Chiou, W.L., 2009. Phenology of 16 species of ferns in a subtropical forest of northeastern Taiwan. Journal of Plant Research 122, 61-67. https://doi.org/10.1007/s10265008-0191-7

Lehn, C.R., Leuchtenberger, C., 2008. Resistência ao fogo de uma população de Cyathea atrovirens (Langsd. \& Fisch.) Domin (Cyatheaceae) no estado do Rio Grande do Sul, Brasil. Biotemas 21, 15-21.

Lehn, C.R., Resende, U.M., 2007. Estrutura populacional e padrão de distribuição espacial de Cyathea delgadii Sternb. (Cyatheaceae) em uma Floresta Estacional Semidecidual no Brasil Central. Revista Biociências 13, 189-195.

Lehn, C.R., Schmitt, J.L., Windisch, P.G., 2002. Aspectos do desenvolvimento vegetativo de Rumohra adiantiformis (Forst.) Ching (Pteridophyta/Dryopteridaceae), em condições naturais. Revista Estadual 25, 21-28.

Lieth, H., 1974. Introduction to phenology and the modeling of seasonality, in: Lieth, H. (Ed.) Phenology and seasonality modeling. Ecological Studies, Berlin-Springer-Verlag, pp. 3-19.

Marques, M.C.M., 2007. Fenologia no limite sul da região tropical: padrões e algumas interpretações, in: Rego, G.M.; Negrelle, R.R.B.; Morellato, L.P.C. Fenologia Ferramenta para Conservação, Melhoramento e Manejo de Recursos Vegetais Arbóreos. Paraná, Embrapa Florestas, pp. 101-112.
Mehltreter, K., 2006. Leaf phenology of the climbing fern Lygodium venustum in a semideciduous lowland forest on the Gulf of Mexico. American Fern Journal 96, 21-30.

Mehltreter, K., Garcia-Franco, J.G., 2008. Leaf phenology and trunk growth of the deciduous tree fern Alsophila firma (Baker) D. S. Conant in a lower montane Mexican forest. American Fern Journal 98, 1-13.

Mehltreter, K., Palacios-Rios, M., 2003. Phenological studies of Acrostichum danaeifolium (Pteridaceae, Pteridophyta) at mangrove site on the Gulf of México. Journal of Tropical Ecology 19, 155-162. https://doi.org/10.1017/S0266467403003171

Mehltreter, K., Sharpe, J. M., 2013. Causes and consequences of the variability of leaf lifespan of ferns. Fern Gazette 19, 193-202.

Moran, R.C., 2004. A natural history of ferns. Timber Press, Portland, Oregon.

Morellato, L.P.C., Alberti, L.F., Hudson, I.L., 2010. Applications of Circular Statistics in Plant Phenology: a Case Studies Approach, in: Keatley, M.; Hudson, I.L. (Org.). Phenological Research: Methods for Environmental and Climate Change Analysis. 1 ed. Springer, pp. 357-371. https://doi.org/10.1007/978-90-4813335-2_16

Morellato, L.P.C., Camargo, M.G.G., Gressler, E., 2013. A Review of Plant Phenology in South and Central America, in: Schwartz, M.D. (Ed.). Phenology: An Integrative Environmental Science, 2 ed. Springer, pp. 91-113. https://doi.org/10.1007/978-94-007-6925-0 6

Morellato, L.P.C., Rodrigues, R.R., Leitão Filho, H.F., Joly, C.A., 1989. Estudo comparativo da fenologia de espécies arbóreas de floresta de altitude e floresta mesófila semi-decídua na Serra do Japi, Jundiaí, São Paulo. Revista Brasileira de Botânica 12, 85-98. http://dx.doi.org/10.1590/S0100- 84042002000 200012

Müller, A., Correa, M.Z., Führ, C.S., Quevedo, D.M., Schmitt, J.L., 2019. Neotropical ferns community phenology: climatic triggers in subtropical climate in Araucaria forest. Ahead of print. https://doi.org/10.1007/s00484-01901755-5

Müller, A., Cunha, S., Junges, F., Schmitt, J.L., 2016. Efeitos climáticos sobre a fenologia de Lindsaea lancea (L.) Bedd. (Lindsaeaceae) em fragmento de floresta atlântica no sul do Brasil. Interciencia 41, 34-39.

Neumann, M.K., Schneider, P.H., Schmitt, J.L., 2014. Phenology, caudex growth and age estimation of Cyathea corcovadensis (Raddi) 
Domin (Cyatheaceae) in a subtropical forest in southern Brazil. Acta Botanica Brasilica 28 (2), 274-280.

https://doi.org/10.1590/S0102-330620140002 $\underline{00014}$

Padoin, T.O.H., Müller, A., Schmitt, J.L., 2016. Fenologia de Blechnum acutum (Desv.) Mett. (Blechnaceae) em Floresta Atlântica Subtropical. Revista Brasileira de Geografia $\begin{array}{llll}\text { Física } & 9 & \text { (6), 1644-1656. }\end{array}$ https://doi.org/10.5935/1984-2295.20160113

PPG I., 2016. A community-derived classification for extant lycophytes and ferns. Journal of Systematics and Evolution 54, 561-603. https://doi.org/10.1111/jse.12229

Puppi, G., 2007. Origin and development of phenology as a science. Italian Journal of Agrometeorology 3, 24-29.

Ranal, M.A., 1995. Estabelecimento de pteridófitas em Mata Mesófila Semidecídua do estado de São Paulo. 3. Fenologia e sobrevivência dos indivíduos. Revista Brasileira de Biologia 55, 777-787.

Schmitt, J.L., Schneider, P.H., Windisch, P.G., 2009. Crescimento do cáudice e fenologia de Dicksonia sellowiana Hook. (Dicksoniaceae) no sul do Brasil. Acta Botanica Brasilica 23, 289-291.

http://dx.doi.org/10.1590/S0102- 33062009000 100030.

Schmitt, J.L., Windisch, P.G., 2003. Relação entre o comprimento do estípete, produção de frondes e tamanho do cáudice, em Alsophila setosa Kaulf. (Pteridophyra, Cyatheaceae). Pesquisas, Botânica 53, 55-63.

Schmitt, J.L., Windisch, P.G., 2005. Aspectos ecológicos de Alsophila setosa Kaulf. (Cyatheaceae, Pteridophyta) no Rio Grande do Sul, Brasil. Acta Botanica Brasilica 19 (4), 859865.

http://dx.doi.org/10.1590/S0102- 33062005000 400021

Schmitt, J.L., Windisch, P.G., 2006a. Growth rates and age estimates of Alsophila setosa Kaulf. in southern Brazil. American Fern Journal 96, 103-111.

Schmitt, J.L., Windisch, P.G., 2006b. Phenological aspects of frond production in Alsophila setosa Kaulf. (Cyatheaceae: Pteridophyta) in southern Brazil. Fern Gazette 17, 263-270.

Schmitt, J.L., Windisch, P.G., 2007. Estrutura populacional e desenvolvimento da fase esporofítica de Cyathea delgadii Sternb. (Cyatheaceae, Monilophyta) no Sul do Brasil. Acta Botanica Brasilica 21, 731-740.
https://doi.org/10.1590/S0102- 330620070003 00019

Schmitt, J.L., Windisch, P.G., 2012. Caudex growth and phenology of Cyathea atrovirens (Langsd. \& Fisch.) Domin (Cyatheaceae) in secondary forest, southern Brazil. Brazilian Journal of Biology 72, 397-405. https://doi.org/10.1590/S1519- 698420120002 00023

Seghieri, J., Floret, C.H., Pontanier, R., 1995. Plant phenology in relation to water availibility: herbaceous and woody species in the savannas of northern Cameroon. Journal of Tropical Ecology 11, 237-254. https://doi.org/https://doi.org/10.1017/S026646 7400008713

Sharpe, J. M., Mehltreter, K., 2010. Ecological insights from fern population dynamics, in: Mehltreter, K., Walker, L.R., Sharpe, J.M., (Eds.). Fern Ecology. New York, Cambrigde University Press, pp. 61-102.

Sharpe, J.M., Mehltreter, K., Walker, L.R., 2010. Ecological importance of ferns, in: Mehltreter, K., Walker, L.R.; Sharpe, J.M., (Eds.). Fern Ecology. New York, Cambrigde University Press, pp. 1-18. https://doi.org/ 10.1017/CBO9780511844898.002

Silva, M.M., Farias, R.P., Costa, L.E.N., Barros, I.C.L., 2019. Leaf phenological traits of the tree fern Cyathea praecincta (Cyatheaceae) in a Brazilian lowland tropical forest. Australian Journal of Botany 66, 618-627. https://doi.org/10.1071/BT18084

Souza, K.R.M.S., Alves, G.D., Barros, I.C.L., 2007. Fenologia de Anemia tomentosa (Sav.) Sw. var. anthriscifolia (Schrad.) Mickel em fragmento de Floresta Semidecídua, Nazaré da Mata, Pernambuco, Brasil. Revista Brasileira de Biociências 5, 486-488.

Souza, K.R.M.S., Silva, I.A.A., Farias, R.P., Barros, I.C.L., 2013. Fenologia de três espécies de Adiantum L. (Pteridaceae) em fragmento de Floresta Atlântica no estado de Pernambuco, Brasil. Neotropical Biology and Conservation 2, 96-102. https://doi.org/10.4013/nbc.2013.82.05

US/IBP Phenology Committee, 1972. Annual Report of the United States/International Biological Program Phenology Committee. University of Wisconsin, Milwaukee.

Vianello, R.L., Alves, A.R., 2012. Meteorologia Básica e Aplicações, Editora UFV, Viçosa. 
Windisch, P.G., Pereira-Noronha, M., 1983. Notes on the ecology and development of Plagiogyria fialhoi. American Fern Journal 73, 79-84.

Zuquim, G., Costa, F.R.C., Prado, J., Tuomisto, H., 2008. Guia de samambaias e licófitas da REBIO Uatumã - Amazônia Central. Attema Design Editorial, Manaus. 